Editorial

\title{
Journal of Manufacturing and Materials Processing -A New Open Access Engineering Journal
}

\author{
Steven Y. Liang \\ George W. Woodruff School of Mechanical Engineering, Georgia Institute of Technology, Atlanta, \\ GA 30332-0405, USA; steven.liang@me.gatech.edu; Tel.: +1-404-894-8164
}

Received: 19 April 2017; Accepted: 19 April 2017; Published: 28 April 2017

Journal of Manufacturing and Materials Processing (JMMP) is a new MDPI peer-reviewed, open access venue with a focus on the scientific fundamentals and engineering methodologies of manufacturing and materials processing. MDPI has just marched into its 21st productive year of publishing, with a remarkable slate of over 170 journals, many of which are already archived by Science Citation Index (Web of Science) and Scopus. The intention of the JMMP is to position itself among the elite publication fleet of MDPI in leading the development of scholarly research and rigorous engineering. The goal of the JMMP is to push the forefront of knowledge in the fields of processes, equipment, systems, and materials with relevance to materials processing and manufacturing. It offers a global platform that allows effective exchange of new scientific and engineering ideas and the dissemination of recent, original, and significant research and development findings.

The major dedication of the JMMP is to disseminate novel methodologies of materials processing and manufacturing, design of advanced equipment and tooling, as well as understanding of behaviors and performances that materials exhibit during, and resulting from, fabrication and manufacturing processes. The scope of the JMMP covers the following topical areas: (1) experimental investigation, mechanics analysis, metallurgical examination, and predictive modeling of engineering materials involved in the heating, solidification, deformation, addition, removal, accretion, and other operations in the manufacturing of parts and components; (2) advanced and innovative methodologies for manufacturing and fabrication operations, including mechanical, thermal, optical, chemical, electrical or others (3) development of materials processing methodology to transform material properties and characteristics for subsequent manufacturing steps to be performed; (4) design of equipment or the development of tooling solutions for materials processing and manufacturing; (5) assessment and improvement of process quality, efficiency, and competitiveness; (6) capability enhancement of materials processing and manufacturing through control, measurement, monitoring, and automation; and (7) other topics that may be of interest to the community in the broad context of materials processing and manufacturing operations and systems.

Through competitive peer-review and selective publication of high-quality papers, JMMP aims to strengthen the status of contemporary literature on important issues related to manufacturing and materials processing. The open-access format reduces much of the barriers to circulation thus allowing the speedy dissemination and citation of research results, which has been proven to be beneficial to both the paper contributors and readers. On behalf of the Editorial Board, we extend an invitation to our scientific and engineering colleagues to contribute high-quality, innovative, and ground-breaking research articles to JMMP. The editorial office will strive to maintain rigorous and very efficient review cycles in up-holding the standard of the journal with minimum amount of time-to-publication. There is 
no doubt that $J M M P$ is an exciting new journal to serve the needs of our academic and industry societies, and it shall be opening new frontiers in scholarly pursuits of many important scientific and technological issues.

(C) 2017 by the author. Licensee MDPI, Basel, Switzerland. This article is an open access article distributed under the terms and conditions of the Creative Commons Attribution (CC BY) license (http:/ / creativecommons.org/licenses/by/4.0/). 